\title{
PROBABILISTIC EVALUATION OF LIQUEFACTION-INDUCED GROUND FAILURES TRIGGERED BY SEISMIC LOADING IN URBAN ENVIRONMENT; CASE STUDIES FROM GREECE
}

\author{
Papathanassiou G. ${ }^{1}$, Pavlides S. ${ }^{1}$ \\ ${ }^{1}$ Aristotle University of Thessaloniki, Department of Geology, 54124 Thessaloniki, Greece, \\ gpapatha@auth.gr
}

\begin{abstract}
An issue that should be taken into account by urban planners in Greece, for the extension of urban areas, is the likelihood of earthquake-induced ground deformations. In this paper, information is provided regarding the methodology that is applied for the prediction of liquefaction manifestations in urban environment. In particular, a review of our research concerning the evaluation of the probability of liquefaction-induced ground disruption in three towns, Larissa, Edessa and Lefkada, is presented. The evaluation of probability was achieved using the Liquefaction Potential Index methodology and the relatively classification, introduced in late 80's and modified by Papathanassiou (2008).
\end{abstract}

Key words: liquefaction, urban geology, hazard, Greece

\section{Introduction}

Studies regarding the probabilistic evaluation of liquefaction potential of the geological units in Greece started in the beginning of this decade at the Department of Geology of Aristotle University of Thessaloniki. The occurrence of liquefaction phenomena and the generation of relative failures are crucial issues that should be taken into account regarding the safety of structures within an urban environment due to the seismotectonic regimen and the historical seismicity of the broader Aegean Region. In particular, Greece shows the highest seismicity in Europe and is considered as one of the most prone to earthquakes countries globally. According to the new Greek Seismic Code (EAK 2000), Greece is subdivided into three seismic hazard zones where the design accelerations on seismic bedrock are assigned as $0.16 \mathrm{~g}, 0.24 \mathrm{~g}$ and $0.36 \mathrm{~g}$ for the first, the second, and the third zone, respectively. However, regarding the local scale studies, the influence of site-effects should be taken into account for the estimation of the surface acceleration instead of the provided by EAK parameters of the design acceleration, a, which should be mainly employed in regional scale maps.

Furthermore, the susceptibility to liquefaction of several areas in Greece is shown by Papathanassiou et al. (2005), where a map of historical liquefaction occurrences in broader Aegean region, including Greece, is compiled based on descriptions included in seismic catalogues and primary sources. The outcome provided by this study is that these types of secondary effects reoccur within specific areas in Greece particularly in Thessaly, Ionian Islands and the Gulf of Corinth including the urban environments of the town of Larissa, Aeghio and Corinth.

Liquefaction is the transformation of saturated granular material from a solid state to a liquid state 
as a consequence of increased pore pressures that reduce the effective strength of the material (Youd 1973). The liquefaction of a subsoil layer may induced surface disruption such as ground settlements, sand boils and lateral spreading and leads to structural damages at buildings, pipelines, bridges etc. Areas susceptible to liquefaction can be identified through detailed geologic, geomorphic and hydrologic mapping (Witter et al.2006) while the liquefaction potential is evaluated based on data regarding the susceptibility to liquefaction of the soil layer and the expected value of ground motion triggered by the earthquake.

In order to evaluate the liquefaction potential of a subsoil layer, the procedure proposed by Youd et al. (2001) is usually applied. According to this procedure, the ability of a soil element to resist liquefaction is defined as factor of safety against liquefaction, Fs, and two variables are required for its calculation: the cyclic resistance ratio CRR and the earthquake induced cyclic stress ratio CSR at a specific depth for a given design earthquake. This deterministic approach has been modified the last decade by several researchers who proposed probabilistic-based approaches for the assessment of the liquefaction potential of a soil layer. Among them, the procedures proposed by Seed et al (2003) and Boulanger and Idriss (2004) were the most known methodologies that are applied by engineers and geologists.

In addition, Iwasaki et al. (1978), proposed an index (LPI) for the evaluation of liquefaction potential of a site instead of a soil layer. The advantage of LPI is that it quantifies the likely of liquefaction of the site, by providing a unique value for the entire soil column instead of several factors of safety per layer. Therefore, the values of LPI were used for the compilation of liquefaction hazard maps. These maps comprise a preliminary assessing tool of the liquefaction potential and can be used by decision makers for urban planning purposes.

In this study, a review of liquefaction studies performed in Greece is presented, regarding the evaluation of liquefaction potential in three towns; Lefkada, Larissa and Edessa. The goal of our research was twofold; a. evaluation of the surficial acceleration using different methodologies and $b$. focus on the role of the site conditions in comparison to the proposed by EAK values of ground motion and computation of the probability of liquefaction surface occurrence at these towns. The employed values of surface acceleration in our analysis were either recorded by accelerometers or estimated using 1-D site response analysis and geology-based proposed amplification factors. The liquefaction potential and the probability of liquefaction-induced ground disruption phenomena were evaluated using the approaches proposed by Iwasaki et al. (1978) and Papathanassiou (2008), respectively.

\section{Liquefaction-induced failures in urban environment}

Reports describing liquefaction related phenomena within the Aegean broader region can be found in seismic catalogues and primary sources from 1509 A.C. (Papathanassiou et al. 2005). Large scale manifestations were reported and mapped by Schmidt (1867) regarding the Aeghio 1861earthquake while the first event that occurred close to an urban environment and studied in detail was the 1906 San Francisco earthquake. However, the most severe liquefaction-induced damages to civil infrastructure were observed after the Niigata and Anchorage earthquakes in 1964 which helped to identify liquefaction as a major problem within an urban area (Idriss and Boulanger 2008). Other major events that provided data regarding the occurrence of liquefaction were the 1989 Loma Prieta and the 1995 Kobe earthquakes. The latter event caused pervasive liquefaction throughout the reclaimed lands and the manmade islands in the Kobe region, causing extensive structural damages to quay walls around the port facilities and associated damage to the cranes and other supporting facilities (Idriss and Boulanger 2008). 
Moreover, during the last decade of the 20th century two large earthquakes occurred in Turkey and Taiwan in 1999 that induced severe damages to the cities of Adapazari, Izmit, Golcuk and Nantou, Yuanlin, Wufeng, respectively. Data provided by post earthquake reconnaissance reports, performed in these urban areas, became the base layer for the modification of existing methodologies and for the introduction of new probabilistic approaches regarding the liquefaction hazard in urban environments.

In particular, sand boiling and lateral spreading were reported in association with coastal failures and the permanent displacements in horizontal and vertical directions due to lateral spreading ranged between 60 and $480 \mathrm{~cm}$ and 28 and $110 \mathrm{~cm}$, respectively (Aydan and Ulusay 2000). The incidents of liquefaction phenomena were mainly observed in inland alluvial areas and along coastal areas inducing damage to ports and industrial facilities but some occurred in the free field away from the structures (Sonmez et al. 2008). The Chi-Chi earthquake (Taiwan) occurred in 1999 and induced the damages and collapses of bridges, port facilities and buildings. According to Yuan et al. (2003) among the 39 districts of the city of Yuanlin the 17 were found to have suffered significant settlement and 8 were found to have obvious liquefaction evidence such as sand boils (Sonmez et al. 2008).

Regarding Greece, the most severe liquefaction-induced structures damages within an urban area were reported at the waterfront area of the town of Lefkada. According to Papathanassiou et al. (2005) liquefaction occurrences (sand boils and vent fractures) were observed mainly in the waterfront area, and caused damages to pavements and sidewalks behind seawalls. In addition, severe damages to port facilities, probably due to liquefaction of the subsoil layers, were observed at the towns of Argostoli, Lixouri and Zakynthos after the devastating 1953 earthquake.

\section{Methods for estimating the liquefaction potential}

\subsection{Evaluating the liquefaction susceptibility and the potential of the soil layers}

The evaluation of liquefaction susceptibility used to be realized by applying the "Chinese" criteria (Wang, 1979) or the guidelines proposed by Andrews and Martin (2000). Both of these criteria taken into account the appearance of fine grain sized material in the soil element and particularly the percent of clay size. However, published papers by Seed et al. (2003) and Bray and Sancio (2006) stated that the plasticity behavior of fine size particles of soils is more important than the percent of claysize fines. Thus, they proposed new criteria where soils with fines content more than $35 \%$ are considered as potentially liquefiable when its liquid limit is less than $37 \%$ and the plasticity index is less than $12 \%$ while the water content is high relative to their liquid limit (Seed et al. 2003).

Having evaluated the liquefaction susceptibility of the soil layers, the computation of the factor of safety should be performed. According to Youd et al. (2001) the factor of safety, Fs, is the ratio between the cyclic resistance ratio CRR and the earthquake induced cyclic stress ratio CSR.

The CSR is expressed as:

$$
C S R=0.65 \times\left(\frac{a_{\max }}{g}\right) \times\left(\frac{\sigma_{v o}}{\sigma_{v o}^{\prime}}\right) \times r_{d}
$$

Where $\sigma_{\mathrm{vo}}$ : total vertical stress at depth $\mathrm{z}, \sigma_{v_{\mathrm{o}}}$ : effective vertical stress at the same depth, a $\max :$ peak horizontal ground acceleration, $g$ : acceleration due to gravity and $r_{d}$ : stress reduction factor. In this study, the term rd was estimated using the Liao and Whitman (1986) equation: 


$$
\begin{gathered}
r_{d}=1.0-0.00765 \times z \text { for } \mathrm{z}<9.15 \mathrm{~m} \\
r_{d}=1.174-0.0267 \times z \text { for } 9.15 \mathrm{~m}<\mathrm{z}<23 \mathrm{~m}
\end{gathered}
$$

Finally, the CSR values have been divided by the magnitude scaling factor, MSF, which is calculated by the following equation, Youd et al. (2001):

$$
M S F=\left(\frac{M w}{7.5}\right)^{2.56}
$$

Afterwards, the CRR, is computed using the following equation (Youd et al. 2001)

$$
C R R=\frac{1}{34-N_{1(60)}}+\frac{N_{1(60)}}{135}+\frac{50}{\left[10 \times N_{1(60)}+45\right]^{2}}-\frac{1}{200}
$$

The calculation of $\mathrm{N}_{1(60)}$ is influenced by the measured standard penetration resistance $\mathrm{N}$, the overburden pressure factor $\mathrm{Cn}$, the correction for hammer energy ratio (ER) Ce, the correction for borehole diameter, $\mathrm{Cb}$ the correction factor for rod length $\mathrm{Cr}$ and the correction for samplers with or without liners. The $\mathrm{Cn}$ was calculated according to the equation proposed by Liao and Whitman (1986), $\mathrm{Cn}=\left(\mathrm{Pa} / \sigma_{\mathrm{vo}}\right)^{0.5}$, while the others factors were estimated using the parameters suggested by Youd et al. (2001). Additionally, a "fine content" correction was applied to the calculated $\mathrm{N}_{1(60)}$ value in order to obtain an equivalent clean sand value $\mathrm{N}_{1(60) \text { cs }}$ given by the equations proposed by Youd et al. (2001).

\subsection{Estimating the surface acceleration value}

A critical issue regarding the compilation of hazard maps in urban environment is to evaluate the earthquake parameters at the ground surface since the proposed by Greek Seismic code values should only be used for regional scale maps. In particular, the employed $a_{\max }$ should be estimated based either on ground motion recorded close to the study area or using geology-based amplification factors or performing 1-D site response analysis. Regarding the case studies that are presented in this review, the estimation of $a_{\max }$ was achieved based on these three options.

In order to account for amplification effect due to surface geology, the regression proposed by Stewart et al. (2003) can be used. In particular, the amplification factor, $\mathrm{f}$, and the surface acceleration $\mathrm{a}_{\max }$ are computed using the equations proposed by Stewart et al. (2003):

$$
\begin{gathered}
\operatorname{Ln}(\mathrm{f})=\mathrm{a}+\mathrm{b} \ln (\mathrm{PGA}) \\
\mathrm{a}_{\max }=\mathrm{PGA}^{* \mathrm{f}}
\end{gathered}
$$

where $\mathrm{f}$ is the amplification factor; $\mathrm{a}, \mathrm{b}$ are parameters depending on the age and the material texture of soil; and PGA is the value of design acceleration on rock outcrop conditions; $\mathrm{a}_{\max }$ is the value of surface acceleration which is employed on the evaluation of liquefaction potential.

A more sophisticated method, for the estimation of surface acceleration value is achieved by performing site response analyses. In particular, 1D analysis are based on shear wave velocities Vs values of the subsoil layers and real acceleration time histories that are selected with respect to the type of causative fault, the magnitude of the earthquake and the geological conditions at the recorded 
station. A web site where time histories can be downloaded is the European Strong motion Database (ESD) www.isesd.cv.ic.ac.uk/ESD. Afterwards, a scaling based on the value of the design acceleration of Greek Seismic code is suggested and the scaled PGA time histories can be used as input motion in order to estimate the value of acceleration on ground surface.

\subsection{Liquefaction Potential Index}

The evaluation of liquefaction potential in urban areas can be finally achieved based on the Liquefaction Potential Index approach proposed by Iwasaki et al. (1978; 1982). The index is proportional to the thickness of the liquefiable layer, the thickness of the non-liquefiable (cap) layer and the value of the factor of safety against liquefaction and is defined as:

$$
L P I=\int_{0}^{z} F(z) W(z) d z
$$

Where $\mathrm{z}$ is the depth below the ground surface in meters; $\mathrm{F}(\mathrm{z})$ is a function of the factor of safety against liquefaction, Fs, where $\mathrm{F}(\mathrm{z})=1$-Fs when $\mathrm{Fs}<0.95, \mathrm{~F}(\mathrm{z})=2.106 \mathrm{e}-18.427 \mathrm{Fs}$ if $0.95<\mathrm{Fs}<1.2$ and if $\mathrm{Fs}>1.2, \mathrm{~F}(\mathrm{z})=0$ (Sonmez, 2003). Equation (1) gives the values of LPI ranging from 0 to 100 .

Iwasaki et al. (1982) calibrated the severity of liquefaction-induced damages with the LPI values using data provided by 87 SPT borings in liquefied and non-liquefied sites in Japan. According to this calibration, liquefaction failure potential has been characterized as high where LPI ranges between 5 and 15 and low at sites where $0<\mathrm{LPI}<5$. The liquefaction potential is extremely low where LPI is equal to 0 , and extremely high at sites where LPI $>15$. The LPI methodology was modified by Sonmez (2003), by adding a threshold value of 1.2 instead of 1 of the factor of safety and by introducing two new categories of potential, "non-liquefiable" and "moderate". At sites where LPI values range between 2 and 5 the potential was defined as moderate, while where LPI ranges between 0 and 2 the site was characterized as low liquefaction potential area. Finally, sites where the LPI value is equal to zero were characterized as non liquefiable (Sonmez 2003).

Furthermore, Toprak and Holzer (2003) attempted to relate LPI with the severity of the surface manifestations of liquefaction, using CPT's from the 1989 Loma Prieta, California earthquake. They observed that the median values of LPI were 5 and 12 , respectively, in areas with sand boils and lateral spreads. Lower and upper quartiles were 3 and 10 for sand boils and 5 and 17 for lateral spreads. Recently, Papathanassiou (2008) proposed a new calibration that resulted from the application of the box-whisker plot method to data provided by borings with SPT. According to this study, at sites where LPI $>32$ liquefaction-induced failures of "high" degree, such as lateral spreading phenomena, are likely to occur, while at sites where LPI $<19$ no liquefaction manifestations should be expected. At sites where the LPI value ranges between 19 and 29, "medium" degree of severity liquefaction surface evidence, such as sand boils and ejection of material is likely to occur. As it is stated by Papathanassiou (2008), a reason for the differences among the threshold LPI proposed by Iwasaki et al. (1982), Toprak and Holzer (2003) and Papathanassiou (2008) is that in the latter study the evaluation of liquefaction susceptibility of soil layers was based on the modified criteria proposed by Seed et al. (2003) in lieu of "Chinese criteria".

Moreover, Lee at al. (2003) re calibrated the scale, based on CPT data conducted in liquefied sites in Taiwan after the 1999 Chi-Chi earthquake, proposing that liquefaction potential of a site is very high and low where LPI is greater than 30 and less than 20 respectively, while where LPI values range between 20 and 30 the potential is characterized as medium. Sonmez and Gokceoglu (2005) 
used the probability of liquefaction PL in lieu of factor of safety in order to compute the LPI or Liquefaction Severity Index Ls, as they named it in their paper, and they proposed a new classification. Furthermore, Li et al. (2006) also defined the LPI or IL as a function of probability of liquefaction and they proposed mathematical formula for the evaluation of the probability of liquefaction-induced ground failure. Finally, Papathanassiou (2008) using a logistic regression analyses, proposed a LPI-based approach for the calculation of the probability of liquefaction manifestations. For a comprehensive description of these procedures, the reader is referred to Holzer (2008).

The advantage of LPI is that it quantifies the likely of liquefaction of the site, by providing a unique value for the entire soil column instead of several factors of safety per layer. Therefore, the values of LPI were used for the compilation of liquefaction hazard maps. These maps comprise a preliminary assessing tool of the liquefaction potential and can be used by decision makers for urban planning purposes. Such thematic maps were published for Busehr, Iran (Hosseini 1998), for the state of California, USA (Holzer et al. 2002), for the town of Inegol, Turkey (Sonmez 2003; Sonmez and Gokceoglou (2005), for the town of Ceyhan, Turkey (Ulusay and Kuru 2004), and for the city of Lefkada, Greece (Papathanassiou et al. 2005), California, U.S.A by Lenz and Baise (2007) and Memphis, U.S.A (Cramer et al. 2008)

\section{Evaluating the probability of surface liquefaction occurrence in urban environ- ments: case studies in Greece}

As it is mentioned in previous section, the assessment of liquefaction hazard within urban areas is a crucial issue in order to avoid possible structural damages triggered by earthquakes. This can be achieved by applying the methodology of Liquefaction Potential Index and afterwards, by correlating the estimating LPI values with the liquefaction potential as it is described in published classifications (Iwasaki et al. 1978; Sonmez 2003). Another approach for showing the hazard due to liquefaction is the compilation of a probability-based map, using suggested probabilistic regressions provided by statistical analysis (logistic regression, discriminant, Bayesian method).

In this article, cases studies from Greece are going to be presented where liquefaction hazard maps were compiled based on either the classification of LPI values with liquefaction potential proposed by Iwasaki et al. (1978) or based on the probability of liquefaction surface occurrences that was computed using the regression proposed by Papathanassiou (2008). These case studies were selected due to the fact that are located at different seismic hazard zones according to EAK (2000), thus including a variety in the earthquake magnitude. Regarding the estimation of the value of surface acceleration, three different approaches were applied and resulted to different acceleration values than the proposed by EAK (2000) ones, indicating the importance of performing site-specific analyses within an urban environment. In particular, in the first case (Lefkada) the employed value of $\mathrm{a}_{\max }$, for the calculation of LPI, was recorded within the urban area during the Lefkada 2003 earthquake, in the second case study, the town of Edessa, the surface acceleration was estimated based on 1-D site response analysis and finally, in the third case, the town of Larissa, the $\mathrm{a}_{\max }$ was estimated using geology-based amplification factors.

\subsection{Lefkada}

Within the urban area of the town of Lefkada, liquefaction phenomena have been reported more than one time according to the historical catalogue of liquefaction manifestations published by Papathanassiou et al. (2005). The latest event occurred in 2003 and triggered soil liquefaction and related damages mainly to port facilities. As it was reported by Papathanassiou et al. (2005) in the 
town of Lefkada, liquefaction of the subsoil layers caused damages to pavements and sidewalks behind seawalls. According to eyewitnesses, muddy water was ejected at a height of $50 \mathrm{~cm}$ from cracks in a pavement surface near the waterfront, indicating high excess pore pressure generating during earthquake shaking. Furthermore, we observed that the asphalt pavement was covered by a thin sandy-silty layer which was ejected from the ground fissures. The length of the fissures varied from few meters to tens of $\mathrm{m}$ and their width from a few $\mathrm{mm}$ to $8 \mathrm{~cm}$.

In order to evaluate the liquefaction potential of the subsoil at the urban area of Lefkada, data provided by boreholes that were performed during post reconnaissance field surveys, were collected. Using this information, the liquefaction susceptibility and the factor of safety of the soil layers were estimated. The employed earthquake characteristics were equal to $\mathrm{a}_{\max }=0.4 \mathrm{~g}$, recorded by the permanent network of ITSAK (Institute of Engineering Seismology and Earthquake Engineering) during the main shock at the center of the city, while the Ms value corresponds to the one of the 2003 earthquake $(\mathrm{Ms}=6.4)$, and is similar to the maximum earthquake magnitude that occurred in Lefkada island (after 1911) according to historical seismicity of the area.

Afterwards, the LPI value per borehole was computed based on Iwasaki et al. (1978) methodology and a map of liquefaction potential was compiled using the proposed classification. The predicted areas of high liquefaction potential are in agreement with the sites where liquefaction-induced ground failures were triggered by the 2003 Lefkada earthquake, indicating that LPI may be a useful tool for future seismic hazards studies.

\subsection{Edessa}

The case study of the town of Edessa was more complicated due to the fact that the geology and the topography of the area indicate that an amplification of the ground motion is possible. Thus, we concluded that the proposed value of PGA, 0.16g, by the EAK (2000) is not representative for a "microzonation" study and we decided to perform 1-D site response analysis using data provided by seven borings with SPT. In order to achieve this, several real acceleration time histories were selected with respect to the type of causative fault, the magnitude of the earthquake and the geological conditions at the recorded station, and were downloaded by the web site of European Strong motion Database (ESD) www.isesd.cv.ic.ac.uk/ESD (Papathanassiou and Valkaniotis, 2009).

Afterwards, the input acceleration time histories have been chosen for scaling based on the value of the design acceleration of Greek Seismic code and the scaled time histories were used as input motion in order to estimate the value of acceleration on ground surface for each one of the seven site. The computed $\mathrm{a}_{\max }$ values at the sites that were estimated using the EERA software proposed by Bardet et al. (2000).

Having estimated the $\mathrm{a}_{\max }$, we proceeded to the computation of LPI values based on seven geotechnical profiles that were provided by the boreholes. In addition, the probability of liquefaction surface evidence per site was computed using the proposed by Papathanassiou (2008) LPI-based equation:

$$
\operatorname{Pr} o b(\text { liquefaction })=\left(\frac{1}{1+e^{-(-3.092+0.218 \times L P I)}}\right)
$$

The outcome of this study indicates that when the $\mathrm{a}_{\max }$ is equal to the proposed by the EAK (2000) no liquefaction-induced surface disruption is expected. However, liquefaction phenomena, such as 
sand boils, are expected to be triggered when the amplification of the ground motion due to local geology is taken into account. This result is in agreement with the secondary effects triggered by the 1395 event that occurred close to the town of Edessa.

\subsection{Larissa}

The third case study that is presented in this article deals with the assessment of liquefaction hazard at the urban area of Larissa. This area was selected due to the fact that is classified as a liquefactionprone zone since historical reports exist describing earthquake-induced ground failures, including liquefaction manifestations, triggered by the March $1^{\text {st }} 1941$ earthquake and due to the fact that the town is situated upon sediments deposited by the river of Pinios which traverses the town that are considered as potentially liquefiable.

The estimation of liquefaction potential and the computation of the probability of liquefaction surface evidence were achieved using data provided by geotechnical profiles of borings with SPT and based on the LPI methodology and the LPI-based regressions proposed by Iwasaki et al . (1978) and Papathanassiou (2008), respectively. In addition, in order to estimate the surface acceleration values of the ground motion, the provided design acceleration value of EAK (2000) was used as a baseline layer and afterwards, for every site an $a_{\max }$ value was estimated using geology-based amplification factors, as they were proposed by Stewart et al. (2003).

The outcome of this research shows that the occurrence of liquefaction surface evidences is likely only at two areas close to river Pinios, although the fact that it was expected to be triggered in more places. This result could be explained by the fact that the majority of susceptible to liquefaction layers are not loose enough (SPT-N $>25)$ to be liquefied under this seismic scenario and that the average depth of the groundwater table is more than 4 meters.

\section{Conclusions-Results}

The basic aim of this article is to present the methodologies that are applied for the evaluation of liquefaction potential of subsoil layers and for the compilation of liquefaction hazard maps in urban environments. Furthermore, a brief presentation regarding the importance of the site-specific conditions is given and three different approaches for the estimation of the surface acceleration that are used for the computation of factor of safety against liquefaction are proposed.

This goal is achieved by analyzing the most-known methods and their applications in urban areas, presenting examples from Greece. In particular, three case studies are presented, representing the towns of Lefkada, Larissa and Edessa, where liquefaction hazard maps were already compiled. Regarding the town of Lefkada, the validation of the LPI-based liquefaction potential map was realized by comparing it with the earthquake-induced liquefaction phenomena distribution while the provided probability map of liquefaction surface occurrence of the town of Edessa was validated using the information regarding the 1395 earthquake secondary effects. Finally, the areas where liquefaction phenomena are expected to be triggered within the urban area of Larissa are in agreement with the distribution of land sliding and liquefaction manifestations triggered by the March, $1^{\text {st }} 1941$ Larissa earthquake. As an outcome of these studies, we concluded that within urban areas in earthquake prone countries it is important to evaluate the liquefaction hazard since by this way it is possible to delineate areas where structural damages due to liquefaction of the subsoil layers are expected to occur.

\section{References}


Andrews, D.C. and Martin, G.R., 2000. Criteria for liquefaction of silty sands, in: $12^{\text {th }}$ World Conference on Earthquake Engineering, Auckland, New Zealand

Aydan, O. and Ulusay, R., 2000. A preliminary investigation report for a collaborative research on the liquefaction and faulting-induced ground deformations and associated damages in 1999 Kocaeli earthquake region, Ankara (unpublished)

Bardet, J, Ichii, K. and Lin, C., 2000. EERA, a computer program for equivalent linear earthquake site response analysis of layered soil deposits. WWW document URL, University of Southern California, $38 \mathrm{pp}$

Boulanger, R.W., and Idriss, I.M., 2004. Evaluating the potential for liquefaction or cyclic failure of silts and clays, Report No UCD/CGM-04/01, Center for geotechnical modeling, University of California, Davis.

Bray, J.D. and Sancio, R.B., 2006. Assessment of the Liquefaction Susceptibility of Fine-Grained Soils, Journal of Geotechnical and Geoenvironmental Engineering, ASCE, 132(9): 1165-1177

Cramer, C.H., Rix, G.J. and Tucker, K. 2008. Probabilistic liquefaction hazard maps for Memphis, Tennessee. Seismological Research Letters, 78 (in press).

EAK, 2000. Greek Seismic Code, OASP, Athens, 72 pp and 7 Appendixes

Hosseini, S.M.M.M. 1998. Microzonation for liquefaction in Busehr, Iran. Proc. 11th European Conference on Earthquake Engineering (CD-ROM), A.A. Balkema, Rotterdam

Holzer T.L., Bennett M.J., Noce T.E., Padovani A.C. and Tinsley J.C., III 2002. Liquefaction hazard and shaking amplification maps of Alameda, Berkeley, Emeryville, Oakland, and Piedmont: A digital database. Open-file Report 02-296, U.S. Geological Survey, Menlo Park, CA.

Idriss, I.M. and Boulanger, R.W. 2008. Soil liquefaction during earthquakes, EERI publication, 235 pp

Iwasaki, T., Tatsuoka, F., Tokida, K. and Yasuda, S., 1978. A practical method for assessing soil liquefaction potential based on case studies at various sites in Japan. Proc. 2nd International Conference on Microzonation: 885-896.

Iwasaki, T, Tokida, K, Tatsuoka, F, Watanabe, S, Yasuda, S. and Sato, H. 1982. Microzonation for soil liquefaction potential using simplified methods. In: Proceedings of the 3rd International Conference on microzonation. 3: 1310-1330.

Lenz, J.A. and Baise, L.G. 2007. Spatial variability of liquefaction potential in regional mapping using CPT and SPT data, Soil Dynamics and Earthquake Engineering, 27(7): 690-702

Liao, S. and Whitman, R.V. 1986. Overburden correction factor for SPT in sand, Journal of Geotechnical Engineering, ASCE. 112 (3): 373-377.

Papathanassiou, G. Pavlides, S. Christaras, B. and Pitilakis, K., 2005a. Liquefaction case histories and empirical relations of earthquake magnitude versus distance from the broader Aegean Region, Journal of Geodynamics, 40: 257-278

Papathanassiou G., Pavlides S. and Ganas A. 2005b.The 2003 Lefkada earthquake: Field observations and preliminary microzonation map based on liquefaction potential index for the town of Lefkada. Engineering Geology, 82 (1): 12-31.

Papathanassiou, G. 2008. LPI-based approach for calibrating the severity of liquefaction-induced failures and for assessing the probability of liquefaction surface evidence, Engineering Geology, 96: 94104

Papathanassiou, G. and Valkaniotis, S. 2009. Liquefaction hazard mapping at the town of Edessa, Northern Greece, Natural Hazards, DOI 10.1007/s11069-009-9412-1

Schmidt, J., 1867. Information regarding the 26th of December 1861 earthquake, $52 \mathrm{pp}$. Athens

Seed, R.B., Cetin, O.K., Moss, R.E.S., Kammerer, A.M., Wu, J., Pestana, J.M., Riemer, M.F., Sancio, 
R.B., Bray, J.D., Kayen, R.E. and Faris, A. 2003. Recent advances in soil liquefaction engineering: a unified and consistent framework, 26th annual ASCE L.A. Geot. Spring Sem., Long Beach, California, April 30,71 pp

Sonmez, H. 2003. Modification of the liquefaction potential index and liquefaction susceptibility mapping for a liquefaction-prone area (Inegol, Turkey). Environmental Geology 44(7): 862-871.

Sonmez, H. and Gokceoglu, C. 2005. A liquefaction severity index suggested for engineering practice. Environmental Geology 48(1): 81-91.

Sonmez, B., Ulusay, R. and Sonmez H. 2008. A study on the identification of liquefaction-induced failures on ground surface based on the data from the 1999 Kocaeli and Chi-Chi earthquakes, Engineering Geology, 97: 112-125

Stewart, JP., Liu, AH. and Choi, Y. 2003. Amplification Factors for Spectral Acceleration in Tectonically Active Regions. Bulletin of Seismological Society of America; 93(1): 332-352; DOI: $10.1785 / 0120020049$

Toprak, S. and Holzer, T.L. 2003. Liquefaction potential index: Field assessment.” Journal of Geotechnical Geoenvironmental Engineering 129(4): 315-322.

Wang, W. 1979. Some findings in soil liquefaction, Research report, water conservancy and hydroelectric power scientific research institute, Beijing, August.

Witter, C.R., Knudsen, L.K., Sowers, M.J., Wentworth, M.C., Koehler, D.R. and Randolph, C.E. 2006. Maps of Quaternary Deposits and liquefaction susceptibility in the Central San Francisco Bay Regio, California, Open file report 2006-1037, USGS, 43 pp.

Youd, T.L. 1973. Liquefaction, flow and associated ground failure: U.S. Geological Survey Circular 688, $12 \mathrm{pp}$.

Youd, T.L., Idriss, I.M., Andrus, R.D., Arango, I., Castro, G., Christian, J.T., Dobry, R., Finn, W.D.L., Harder, L.F., Hynes, M.E., Ishihara, K., Koester, J.P., Liao, S.S.C., Marcurson, III WF, Marti, G.R., Mitchell, J.K., Moriwaki, Y., Power, M.S., Robertson, P.K., Seed, R.B., and Stokoe II K.H. 2001. Liquefaction resistance of soils: summary report from the 1996 NCEER and 1998 NCEER/NSF workshops on evaluation of liquefaction resistance of soils, Journal of Geotechnical Geoenvironmental Engineering, 817-833

Yuan, H., Yang, S.H., Andrus, R.D. and Juang, H. 2003. Liquefaction-induced ground failure: a study of the Chi-Chi earthquake cases. Engineering Geology, 71: 141-155 